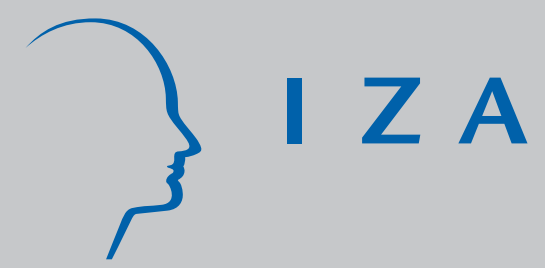

IZA DP No. 4551

Labor Market Discrimination and Capital Investment: The Effects of Fan Discrimination on Stadium Investment

Örn B. Bodvarsson

Brad R. Humphreys

November 2009 


\title{
Labor Market Discrimination and Capital Investment: The Effects of Fan Discrimination on Stadium Investment
}

\author{
Örn B. Bodvarsson \\ St. Cloud State University \\ and IZA \\ Brad R. Humphreys \\ University of Alberta \\ Discussion Paper No. 4551 \\ November 2009 \\ IZA \\ P.O. Box 7240 \\ 53072 Bonn \\ Germany \\ Phone: +49-228-3894-0 \\ Fax: +49-228-3894-180 \\ E-mail: iza@iza.org
}

Any opinions expressed here are those of the author(s) and not those of IZA. Research published in this series may include views on policy, but the institute itself takes no institutional policy positions.

The Institute for the Study of Labor (IZA) in Bonn is a local and virtual international research center and a place of communication between science, politics and business. IZA is an independent nonprofit organization supported by Deutsche Post Foundation. The center is associated with the University of Bonn and offers a stimulating research environment through its international network, workshops and conferences, data service, project support, research visits and doctoral program. IZA engages in (i) original and internationally competitive research in all fields of labor economics, (ii) development of policy concepts, and (iii) dissemination of research results and concepts to the interested public.

IZA Discussion Papers often represent preliminary work and are circulated to encourage discussion. Citation of such a paper should account for its provisional character. A revised version may be available directly from the author. 
IZA Discussion Paper No. 4551

November 2009

\section{ABSTRACT \\ Labor Market Discrimination and Capital Investment: The Effects of Fan Discrimination on Stadium Investment ${ }^{*}$}

We investigate the possibility that labor market discrimination affects economic outcomes in the complementary capital market. Previous research contains ample theoretical justification, and empirical evidence, that discrimination affects wages and employment in labor markets. However, the effects of discrimination against minority labor on transactions in markets for other inputs used in production are not known. We develop a model of the optimal capital stock put in place in the presence of customer discrimination and test this model using data on sports facility construction over the period 1950-2004. The empirical evidence suggests that teams in cities with more racial segregation spend less on sports facilities, confirming the predictions of the model about the effect of customer discrimination on capital investment.

JEL Classification: J15

Keywords: racial discrimination, capital stock, complementarity, stadium financing

Corresponding author:

Örn B. Bodvarsson

Department of Economics

St. Cloud State University

St. Cloud, MN 56301-4498

USA

E-mail: obbodvarsson@stcloudstate.edu

\footnotetext{
* We thank Dennis Coates and Kirk Kerr for a number of helpful comments and Maya Skowron and Tiffany Richardson for their outstanding research assistance.
} 


\section{Introduction}

Since the pioneering work of Becker (1971), economists have examined the causes and consequences of discrimination in labor markets from a theoretical and empirical perspective. Curiously, little attention has been paid to the possibility that the effects of discrimination in labor markets may also affect the use and prices of other inputs in production. For example, if labor and capital are complementary or substitute inputs in production, discrimination against the labor force may increase or reduce the optimal amount of capital the firm will acquire. At first blush, this omission seems somewhat odd, given that economic theory clearly highlights the inter-related nature of a firm's decisions about labor and capital in the production process. However, the effects of discrimination are clearly discernable in labor markets, where large gaps in the earnings of workers of different races with similar levels of education and experience are observable and data are abundant. Concern about the equity and efficiency implications of labor market discrimination fueled interest in this area. In contrast, capital markets function on a different time scale than labor markets, capital is more persistent than labor inputs, and most data from capital markets are aggregated over both firms and time making it difficult to control for most sources of discrimination in empirical research. Given these differences, the lack of attention paid to discrimination in capital markets is understandable.

Becker's (1971) model of discrimination posits that discrimination begins with an individual's tastes or preferences. This model identified three possible sources of discrimination: tastes of employees, employers, or customers. According to this model, employees prefer to work with people with similar characteristics, employers prefer to hire such workers, and customers prefer to purchase goods and services produced and sold by such people. Note that the model does not predict that workers, employers, and customers will only associate with people of the same race, just that they have tastes for these characteristics. These tastes for discrimination have effects on wages, prices, costs, and revenues in product and input markets, and lead to observable economic phenomena like earnings gaps and occupational segregation.

In this paper, we investigate the possibility that the effects of discrimination extend beyond labor markets into capital markets. We present theoretical and empirical evidence that a firm's decisions about the optimum stock of capital will be influenced by customer discrimination. First, we develop a model of firm behavior that accounts for the firm's customers' preferences regarding the race of the workers that produce the firm's products. This model generates predictions about the effect of customer discrimination on the amount of capital put in place by firms. Second, we test the predictions of this model using data on new sports stadium and arena construction by professional football, basketball, baseball and hockey franchises in the United States over the past 100 years.

The existence and effects of discrimination in sports labor markets have received considerable 
attention from economists. Kahn (1991) surveyed this extensive literature and discussed dozens of empirical studies of employer, employee and customer discrimination, as well as a handful of studies of gender discrimination, published over the past forty years. In the fifteen years since Kahn's survey, the literature on discrimination in sports labor markets has continued to grow. Recent research on discrimination in sports includes papers by Szymanski (2000), who found evidence of discrimination in English professional football over the period 1978-1993, Kanazawa and Funk (2001) who found evidence of discrimination in Nielson ratings for locally televised professional basketball games, and Groothius and Hill (2004) who found no evidence of exit discrimination on career length in the NBA. Sports facility construction has also received extensive attention from economists, because of the large public subsidies involved. Coates (2007) recently surveyed this literature.

However, we know of no study that has examined capital markets, in the sports industry or any other industry, for evidence of discrimination. The capital market in the sports industry appears to be a fruitful arena for studying discrimination. There has been a boom in the construction of sports facilities over the past twenty years and sports is an industry where it is easy to observe the racial composition of both individual firms and the markets that these firms operate in. Furthermore, most firms in this industry operate as monopolists in their markets.

In the following section, we develop a model of capital investment in a market where the firm's customers have Becker-style tastes for discrimination and explore the implications of these tastes for the firm's capital investment decisions. Subsequent sections develop an empirical version of this model, describe our data, and discuss the results of our empirical work.

\section{A Theory of Optimal Facility Size with Fan Discrimination}

We develop a model of sports facility investment that includes the demand for admissions by discriminatory sports fans and a production function for admissions that emphasizes complementarity between labor and capital. Who decides how big a facility to build? Often, decisions regarding the choice of labor and capital are made by the same organization, a firm. However, in this case we posit that the party determining sports facility size is usually not the same party who chooses the composition of the team playing in the sports facility. Owners and managers of sports teams decide on the composition of the team roster and other game day inputs, but seldom determine the size of the facility that the team plays in. Local authorities, acting in collaboration with private investors and local voters, typically decide on the type and size of facility to build. For example, 150 new sports facilities have been built in the US since 1958; only 17 of these facilities, just over 11\%, were built and owned by the team. And even in cases of private ownership, facility construction is still subject to some local influence, because of the sizable infrastructure investment that accompanies the construction of a new sports facility and 
the need for construction permits.

The model below focuses on the decision-making process facing local authorities who must decide how big of a sports facility to build. We abstract from the decision-making process facing the sports team. A more general model would consider the optimization problems facing both parties (and the related cooperation/bargaining issues), but such a model would shift the focus of the paper away from the optimal amount of capital to put in place to a more complex joint problem of choosing a team's optimal racial composition (which requires modeling the team's production function). ${ }^{1}$ The model incorporates specific functional forms in order to generate explicit testable predictions to inform our empirical analysis.

Our model shows how customer discrimination can ultimately influence sports facility size. The team chooses some level of racial composition based on the preferences of sports fans, the team's production function (which dictates how white and non-white players are related in production), the markets for white and non-white playing talent, and facility size. Facility size is exogenous to decisions made by the team. In contrast, the stadium authority chooses the facility capacity conditional on the team's choice of optimal team racial composition. The team's racial composition is exogenous to the stadium authority.

The stadium authority seeks to choose a level of stadium capacity that maximizes the net return on admissions. The profitability of stadium admissions depends not only on facility capacity (the amount of capital put in place), but the roster size and quality of the sports team (the labor input) and fan demand for admissions. Accordingly, our model includes a net return function facing the organization that builds and operates a sports facility and also includes:

1. A local market demand function for entertainment provided by a monopoly sports team, which takes account of fan preferences for the team's racial composition. By "market" we mean, for example, the local market for a Major League Baseball team, NFL team, etc. This fits the structure of many local sports markets in the U.S. For example, in the majority of MSAs, there is only one Major League Baseball team providing entertainment in that market;

2. A production function for stadium admissions where capital and labor are complementary; and

3. Stadium financing costs that include partial subsidization by the local government.

We describe each of these components in detail below.

\footnotetext{
${ }^{1}$ See Bodvarsson and Partridge (2001) for an analysis of choice of a sports team's optimal racial composition.
} 


\subsection{Local market demand for sports entertainment}

Suppose that fan demand for sports entertainment depends upon - in addition to price, team success and other traditional demand shifters - the racial compositions of the team and fan population and the racial preferences of fans. We divide the fan market into two segments: white fans and non-white fans. While fans can be prejudiced, we assume that teams and all parties involved in the choice of stadium capacity are assumed to be color-blind. Of course, prejudiced local fans could also be voters on stadium projects, hence customer discrimination could influence voting decisions. However, we abstract from the issue of discrimination in referendum voting on sports facility subsidies, and assume that voters are color-blind. Suppose that white sports fans prefer, all other things equal, a team that has a larger proportion of white players, whereas non-white sports fans prefer a less white team. ${ }^{2}$ If the entire fan market was white, the market demand for stadium admissions would be described by the constant elasticity equation

$$
Q=\left[\frac{\varepsilon\left(\frac{L_{W}}{L}\right)^{\frac{1}{\phi}}}{P}\right]^{\frac{1}{\eta}}
$$

where $Q$ is the number of tickets to events in the sports facility demanded, $P$ is the price of an admission ticket, $L_{W}$ is the number of white players on the team, $L$ is team size (assumed to be fixed), $\phi$ is a parameter reflecting the intensity of white fan preferences for watching white players perform ( $\phi>0$; when white fan preferences get stronger, $\phi$ gets larger), $\eta$ is the inverse of the price elasticity of demand $(0<\eta<1)$, and $\varepsilon$ is a shift variable reflecting other determinants of fan demand, e.g. team success (win-loss percentage or championships won, for example), fan incomes, the size of the fan market, prices of alternative forms of entertainment, non-racial fan tastes, the costs of traveling to the sports facility, etc. In contrast, if the entire fan market was non-white, then market demand for stadium admissions would be

$$
Q=\left[\frac{\varepsilon\left(1-\frac{L_{W}}{L}\right)^{\frac{1}{\delta}}}{P}\right]^{\frac{1}{\eta}}
$$

where $\delta$ is a parameter reflecting the intensity of non-white fan preferences for watching non-white players perform $(\delta>0$; when non-white fan preferences get stronger, $\delta$ gets larger $){ }^{3}$

\footnotetext{
${ }^{2}$ Another approach would be to model white fan distastes for watching non-white players perform and non-white fan distastes for watching white players perform. We take an alternative approach, however, and assume that fans of one skin color have a preference for watching players of their own skin color, all other things equal.

${ }^{3}$ For expositional simplicity, we assume the same price elasticity of demand for non-white fans, as well as the same vector of other demand shifters $(\varepsilon)$. The model's predictions would not change if we relax this assumption.
} 
The fan market is split between a fraction $\mu$ that is white and $(1-\mu)$ that is non-white. Consequently, total market demand for stadium admission is a weighted average of white and non-white fan demand

$$
Q=\mu\left[\frac{\varepsilon\left(\frac{L_{W}}{L}\right)^{\frac{1}{\phi}}}{P}\right]^{\frac{1}{\eta}}+(1-\mu)\left[\frac{\varepsilon\left(1-\frac{L_{W}}{L}\right)^{\frac{1}{\delta}}}{P}\right]^{\frac{1}{\eta}}
$$

Equation (3) has a number of important implications for this analysis. First, there will be conflicting effects on the demand for stadium admissions when the team makes an adjustment in its racial composition. Specifically, when team racial composition is adjusted in order to indulge the racial preferences of one fan group, this necessarily results in weaker demand from the other fan group. Suppose, for example, that the team increases the share of white players ( $\frac{L_{W}}{L}$ rises). This will stimulate ticket demand by white fans (the first term on the right-hand side of equation (3) rises), but it will also reduce demand by non-white fans (the second term on the right-hand side of equation (3) falls). There will thus be a cost to the team of indulging the racial tastes of one segment of the population. We recognize that there could also be a cost to fans of having their racial tastes indulged. For example, if white fans are willing to pay more to see a whiter team play and there are racial differences in player productivity, that may require a team that is not as productive in winning games. If those fans also value team success, they will lose utility from watching a less successful team. We do not include this trade-off between fan value derived from team racial composition and value derived from team performance in our model, although that would be a worthwhile extension of this paper.

The tradeoff between white fan revenues and non-white fan revenues that results from altering team racial composition is illustrated below. Differentiating expression (3) with respect to the share of the team comprised of white players and rearranging terms gives

$$
\frac{\partial Q}{\partial\left(\frac{L_{W}}{L}\right)}=\frac{\mu}{\eta}\left[\frac{\varepsilon\left(\frac{L_{W}}{L}\right)^{\frac{1}{\phi}}}{P}\right]^{\frac{1}{\eta}-1}\left[\frac{\frac{\varepsilon}{\phi}\left(\frac{L_{W}}{L}\right)^{\frac{1}{\phi}-1}}{P}\right]-\frac{1-\mu}{\eta}\left[\frac{\varepsilon\left(1-\frac{L_{W}}{L}\right)^{\frac{1}{\delta}}}{P}\right]^{\frac{1}{\eta}-1}\left[\frac{\frac{\varepsilon}{\delta}\left(1-\frac{L_{W}}{L}\right)^{\frac{1}{\delta}-1}}{P}\right]
$$

The sign of this term, which shows the marginal effect of team racial composition on fan demand, is ambiguous. The first term on the right-hand side of equation (4) measures the gain in white fan demand that results from a whiter team, whereas the second term measures the loss in non-white fan demand that results from those fans having to watch a team with a racial composition less to their liking. Overall fan demand will rise (fall) if the first term exceeds (is less than) the second term. Stadium admissions will net rise when the team gets whiter, provided that the team is sufficiently white to begin with and the white fan base is sufficiently large. In contrast, a whiter team will result 
in lower demand if the team is relatively non-white to begin with and the non-white fan base is sufficiently large. Formally, the sign depends on

$$
\frac{\partial Q}{\partial\left(\frac{L_{W}}{L}\right)} \lessgtr 0 \text { if } \quad \frac{\frac{L_{W}}{L} \mu}{1-\frac{L_{W}}{L}(1-\mu)} \lessgtr \frac{\phi}{\delta} .
$$

Equation (4) implies that making teams even whiter will augment fan demand in markets where fans and sports teams are primarily white. The reason is that white fan demand will be sensitive to a change in team racial composition, whereas non-white fan demand will not. In contrast, if a team increases the white player share in a market fans and teams are primarily non-white, making the team whiter will lead to a net reduction in demand. As the parameter restrictions on the signing of expression (4) indicate, the net effect of team racial composition on fan demand depends on whether the ratio of the share of the team roster that is white weighted by the share of the fan market that is white $\left(\frac{L_{W}}{L}\right) \mu$, to the share of the team roster that is non-white weighted by the share of the fan market that is non-white $\left(\left(1-\frac{L_{W}}{L}\right)(1-\mu)\right)$ is above or below a threshold equaling the ratio of white fan tastes for white players $(\phi)$ to non-white fan tastes for non-white players $(\delta)$. If white fans have very strong tastes for watching white players perform, but non-white fans have relatively mild tastes for watching non-white players, that threshold will be high.

There will also be conflicting effects on fan demand if the racial composition of the sports fan market or the strength of racial tastes change. Consider the effects of a change in the white share of the fan market. Differentiating expression (3) with respect to the white fan share $(\mu)$, we find that the marginal effect of the white fan share on stadium admissions can be positive or negative

$$
\frac{\partial Q}{\partial \mu}=\left[\frac{\varepsilon\left(\frac{L_{W}}{L}\right)^{\frac{1}{\phi}}}{P}\right]^{\frac{1}{\eta}}-\left[\frac{\varepsilon\left(1-\frac{L_{W}}{L}\right)^{\frac{1}{\delta}}}{P}\right]^{\frac{1}{\eta}} \gtrless 0 \text { if }\left(\frac{L_{W}}{L}\right)^{\frac{1}{\phi}} \gtrless\left(\frac{1-L_{W}}{L}\right)^{\frac{1}{\delta}}
$$

According to equation (5), a whiter fan market will result in greater stadium admissions provided that the share of white players on the team is sufficiently high and/or white fan tastes for watching white players are sufficiently strong relative to non-white fan tastes for watching non-white players. The reason is that when the fan market gets whiter, there is an increase in demand attributable to more white fans and a decrease in demand attributable to fewer non-white fans. If the racial composition of the team is sufficiently desirable and white fans value that racial composition strongly, an increase in the white fan share will induce an increase in demand more than sufficient to offset the loss in demand from fewer non-white fans.

A strengthening of white tastes for white teams (an increase in $\phi$ ) or a strengthening of non-white tastes for non-white teams (an increase in $\delta$ ) will have similar sorts of conflicting effects on total market demand, assuming that the total number of sports patrons (one of the variables in vector $\varepsilon$ ) 
is fixed. Also, note that the model predicts important interaction between the fan market and team racial compositions; the size of the marginal effect of a change in white fan market share on demand will be influenced by team racial composition

$$
\frac{\partial^{2} Q}{\partial \mu \partial\left(\frac{L_{W}}{L}\right)}=\frac{1}{\eta}\left[\frac{\varepsilon\left(\frac{L_{W}}{L}\right)^{\frac{1}{\phi}}}{P}\right]^{\frac{1}{\eta}-1}\left[\frac{\frac{\varepsilon}{\phi}\left(\frac{L_{W}}{L}\right)^{\frac{1}{\phi}-1}}{P}\right]+\frac{1}{\eta}\left[\frac{\varepsilon\left(1-\frac{L_{W}}{L}\right)^{\frac{1}{\delta}}}{P}\right]^{\frac{1}{\eta}-1}\left[\frac{\frac{\varepsilon}{\delta}\left(1-\frac{L_{W}}{L}\right)^{\frac{1}{\delta}-1}}{P}\right]>0 .
$$

According to expression (6), if an increase in the share of the white fan market boosts stadium admissions, then the boost will be larger the whiter the team. On the other hand, if stadium admissions fall, the fall will be larger the more non-white the team.

\subsection{The production function for admissions}

Sports entertainment is assumed to be produced with two inputs - labor (players) and capital (the facility) - according to a Cobb-Douglas production function

$$
Q=\Psi K^{\alpha} L^{\beta}
$$

where $K$ is units of capital (e.g. the number of seats), $L$ is the number of players, $\Psi$ reflects the efficiency of production and $\alpha$ and $\beta$ are share parameters. Since the share parameters also reflect relative factor productivity, team success is incorporated into $\beta$. Teams that win more frequently, for example, would have higher values of $\beta$. Since the number of players on a sports team is usually fixed, we assume $L$ to be fixed, hence $\alpha+\beta<1$. Again, local decision makers like stadium authorities make capital input decisions, not the team.

Capital markets are assumed to be perfectly competitive and the supply of capital is perfectly elastic. The market price of capital is $r$ per unit, where $r$ can represent the marginal cost of adding another seat to the stadium or the cost of financing another dollar of construction. Since a team's stadium costs are often at least partially subsidized, we assume that stadium construction is partially subsidized. The marginal cost to the stadium authority of acquiring an additional unit of capital is $(1-\theta) r$, where $\theta$ is the fraction of capital costs that are subsidized. The authority's net returns $\pi$ realized for a given stadium size is

$$
\pi=P \Psi K^{\alpha} L^{\beta}-(1-\theta) r K
$$

and substituting equation (3) into equation (8) using equation (7) gives 


$$
\pi=\varepsilon\left[\mu\left(\frac{L_{W}}{L}\right)^{\frac{1}{\phi \eta}}+(1-\mu)\left(1-\frac{L_{W}}{L}\right)^{\frac{1}{\delta \eta}}\right]^{\eta} \Psi^{1-\eta} K^{\alpha(1-\eta)} L^{\beta(1-\eta)}-(1-\theta) r K
$$

Equation (9) has two novel features that, as we will see later, have important testable implications. First, the returns to capital depend upon team racial composition. All other things equal, a whiter team can raise or lower profits. In other words, customer discrimination affects not only team racial composition, but the deployment of the complementary capital input. Second, stadium profits are influenced by the racial composition of the fan market. If the racial makeup of the population changes, this will ultimately affect the net returns to capital.

\subsection{Optimality conditions}

In solving for the stadium size that maximizes net returns, first order conditions require that facility size be adjusted to a level where the marginal benefit from the last unit of capital acquired equals the subsidy-adjusted marginal cost

$$
\begin{aligned}
& \frac{\partial \pi}{\partial K}=0 \Rightarrow \\
& \varepsilon \alpha(1-\eta)\left[\mu\left(\frac{L_{W}}{L}\right)^{\frac{1}{\phi \eta}}+(1-\mu)\left(1-\frac{L_{W}}{L}\right)^{\frac{1}{\delta \eta}}\right]^{\eta} \Psi^{(1-\eta)} L^{\beta(1-\eta)} K^{(\alpha(1-\eta)-1)}=(1-\theta) r
\end{aligned}
$$

Furthermore, second order conditions require that in order to have an interior solution, there must be diminishing marginal benefits to increasing stadium size

$$
\left.\frac{\partial^{2} \pi}{\partial K^{2}}=\alpha(1-\eta)-1\right)\left(\varepsilon \alpha(1-\eta)\left[\mu\left(\frac{L_{W}}{L}\right)^{\frac{1}{\phi \eta}}+(1-\mu)\left(1-\frac{L_{W}}{L}\right)^{\frac{1}{\delta \eta}}\right]^{\eta} \Psi^{(1-\eta)} L^{\beta(1-\eta)} K^{(\alpha(1-\eta)-2)}\right.
$$

Since $(\alpha(1-\eta)-1)(\varepsilon \alpha(1-\eta))<0$, the sign of the second derivative defined by (11) is negative and thus second order conditions for a maximum are satisfied. To solve for optimal stadium size, set equation (10) equal to zero and solve for $K$, giving

$$
K^{*}=\left[\frac{(1-\theta) r}{\varepsilon \alpha(1-\eta)\left[\mu\left(\frac{L_{W}}{L}\right)^{\frac{1}{\phi \eta}}+(1-\mu)\left(1-\frac{L_{W}}{L}\right)^{\frac{1}{\delta \eta}}\right]^{\eta} \Psi^{(1-\eta)} L^{\beta(1-\eta)}}\right]^{\frac{1}{(\alpha(1-\eta)-1)}}
$$

According to equation (12), optimal stadium size depends upon the price elasticity of demand for stadium admissions $\left(\frac{1}{\eta}\right)$, the strength of fan racial tastes $(\phi$ and $\delta)$, team racial composition, other demand shifters $(\varepsilon)$, efficiencies in production $(\Psi)$, team size $(L)$, the relative productivity of labor and capital ( $\beta$ and $\alpha$, respectively), the stadium subsidy rate $(\theta)$ and the market price of capital. 
Equation (12) yields three sets of predictions. The first set consists of traditional predictions about optimal sports facilities size: optimal facility size and the price of capital are inversely related $(\partial K / \partial r<0)$, optimal facility size rises with the subsidy rate $(\partial K / \partial \theta>0)$ and optimal facility size rises with team size $(\partial K / \partial L>0)$. These three predictions are generally consistent with existing sports facilities, although they have never been derived from a model before to our knowledge.

The second set of predictions relates to the effects of the racial composition of the fan market, fan racial tastes, and team racial composition on stadium capacity:

1. The racial composition of the fan market can affect stadium capacity. The marginal effect of a whiter fan market on optimal stadium size can be positive or negative, depending upon team racial composition and relative fan preferences

$$
\begin{gathered}
\frac{\partial K}{\partial \mu}=-\left(\frac{1}{\alpha(1-\eta)-1}\right)\left[\frac{(1-\theta) r}{\left.\varepsilon \alpha(1-\eta)\left[\mu\left(\frac{L_{W}}{L}\right)^{\frac{1}{\phi \eta}}+(1-\mu)\left(1-\frac{L_{W}}{L}\right)^{\frac{1}{\delta \eta}}\right]^{\eta} \Psi^{(1-\eta)} L^{\beta(1-\eta)}\right]}\right]^{\frac{1}{(\alpha(1-\eta)-1)}-1} \times \\
{\left[\frac{\left.(1-\theta) r \alpha(1-\eta) \eta \varepsilon\left[\mu\left(\frac{L_{W}}{L}\right)^{\frac{1}{\phi \eta}}+(1-\mu)\left(1-\frac{L_{W}}{L}\right)^{\frac{1}{\delta \eta}}\right]^{(\eta-1)} \Psi^{(1-\eta)} L^{\beta(1-\eta)}\right]}{\left[\varepsilon \alpha(1-\eta)\left[\mu\left(\frac{L_{W}}{L}\right)^{\frac{1}{\phi \eta}}+(1-\mu)\left(1-\frac{L_{W}}{L}\right)^{\frac{1}{\delta \eta}}\right]^{\eta} \Psi^{(1-\eta)} L^{\beta(1-\eta)}\right]^{2}}\right]\left[\left(\frac{L_{W}}{L}\right)^{\frac{1}{\phi \eta}}-\left(1-\frac{L_{W}}{L}\right)^{\frac{1}{\delta \eta}}\right]} \\
\gtrless 0 \text { if }\left(\frac{L_{W}}{L}\right)^{\frac{1}{\phi}} \gtrless\left(1-\frac{L_{W}}{L}\right)^{\frac{1}{\delta}}
\end{gathered}
$$

According to equation (13), stadium size rises (falls) when the white share of the fan market rises if the team is sufficiently white (non-white) and the racial preferences of white fans are strong (weak) relative to the racial preferences of non-white fans. The restrictions imposed on the signing of equation (13) are identical to those imposed on the signing of equation (3).

Why does the racial make-up of the fan population matter in the determination of stadium capacity? The reason is that one source of stadium revenue is fan willingness to pay to watch a team with a preferred racial composition. Suppose, for example, that the team is $80 \%$ white, white and non-white fan tastes are equally strong and $\mu$ rises from 0.75 to 0.85 . Since it is assumed that the size of the total fan population remains the same, there are now more white fans and fewer non-white fans. Since the team is relatively attractive to white fans with respect to its racial composition, there will be a relatively large increase in white fan demand. For the non-white segment of the market, willingness to pay with respect to team racial composition is quite low because the team is relatively unattractive to that group. Hence, a drop in the number of non-white fans will not lead to a very large reduction in the demand for stadium 
admissions and there will be a net increase in total demand for stadium admissions. The returns to stadium construction will thus rise and this will induce the construction of a larger stadium. In the extreme case where the team is completely white, there will be no reduction in non-white fan demand.

The net returns to construction arising from a whiter fan market will be even stronger if white fan tastes are stronger than non-white fan tastes. For example, consider the case where $\mu$ rises, but the team is relatively non-white and non-white fan preferences are strong. White fan valuation of the team's racial composition will be very low and non-white valuation will be very high. There will thus be only a very small increase in white fan demand when $\mu$ rises, but a very large decrease in demand coming from non-white fans. Note that if fan tastes for team racial composition are non-existent, then a ceteris paribus change in the racial composition of the fan market will have no effect on the returns to stadium construction and stadium capacity would be unchanged. Therefore, the effects of the racial make-up of the fan pool depend as much on the racial predilections of fans as on the team's racial composition.

2. The racial composition of the team can affect stadium capacity. When the team gets whiter, stadium size can rise or fall, depending upon the team's prior racial composition and how strong white fan preferences are relative to non-white fan preferences

$$
\begin{gathered}
\left.\frac{\partial K}{\partial\left(\frac{L_{W}}{L}\right)=-} \frac{1}{\alpha(1-\eta)-1}\right)\left[\frac{(1-\theta) r}{\left.\varepsilon \alpha(1-\eta)\left[\mu\left(\frac{L_{W}}{L}\right)^{\frac{1}{\phi \eta}}+(1-\mu)\left(1-\frac{L_{W}}{L}\right)^{\frac{1}{\delta \eta}}\right]^{\eta} \Psi^{(1-\eta)} L^{\beta(1-\eta)}\right]}\right]^{\frac{1}{(\alpha(1-\eta)-1)}-1} \times \\
\\
{\left[\frac{(1-\theta) r \alpha(1-\eta) \eta \varepsilon\left[\mu\left(\frac{L_{W}}{L}\right)^{\frac{1}{\phi \eta}}+(1-\mu)\left(1-\frac{L_{W}}{L}\right)^{\frac{1}{\delta \eta}}\right]^{(\eta-1)} \Psi^{(1-\eta)} L^{\beta(1-\eta)}}{\left[\varepsilon \alpha(1-\eta)\left[\mu\left(\frac{L_{W}}{L}\right)^{\frac{1}{\phi \eta}}+(1-\mu)\left(1-\frac{L_{W}}{L}\right)^{\frac{1}{\delta \eta}}\right]^{\eta} \Psi^{(1-\eta)} L^{\beta(1-\eta)}\right]^{2}}\right] \times} \\
{\left[\left(\frac{\mu}{\phi \eta}\right)\left(\frac{L_{W}}{L}\right)^{\frac{1}{\phi \eta}}-1-\left(\frac{1-\mu}{\delta \eta}\right)\left(1-\frac{L_{W}}{L}\right)^{\frac{1}{\delta \eta}}-1\right] \gtrless 0} \\
\text { if } \frac{\left(\frac{L_{W}}{L}\right) \mu}{\left(1-\frac{L_{W}}{L}\right)(1-\mu)} \gtrless \frac{\phi}{\delta}
\end{gathered}
$$

As with equation (13), the behavior of the marginal effect of a change in the share of the team comprising white players on stadium size depends entirely on the underlying fan demand function, with the restrictions for the signing of (14) identical to those for the signing of equation (4). According to expression (14), if the team increases the share of white players, this will induce an increase (decrease) in stadium capacity if the team is relatively white (non-white) to begin 
with and/or the fan market is relatively white (non-white). Furthermore, the threshold values of the team's white player share and the white share of the fan market for the signing of equation (14) depend on how strong white fan preferences are relative to non-white fan preferences.

If the team increases the share of players that is white, this will induce conflicting effects on the demand for stadium admissions. On the one hand, white fan demand will rise because for that segment of the market, the team is now more attractive with respect to its racial composition and white fans will value more watching the team perform. On the other hand, non-white fan demand will fall because the team is now less attractive, racially speaking, and those fans will value less watching the team perform. If the white share of the team is high to begin with and the fan market is primarily white, then the boost in fan demand will be substantial relative to the drop in non-white fan demand. The net return to stadium construction will be positive, inducing larger stadium capacity. On the other hand, if the white share of the team is low to begin with and the fan market is primarily non-white, the boost in fan demand will be small relative to the drop in non-white fan demand, resulting ultimately in a smaller stadium.

3. The strength of fan tastes for team racial composition will affect the stadium construction decision. If white fan tastes strengthen (weaken), then for a given team racial composition, stadium size will grow (shrink); if non-white fan tastes strengthen (weaken), stadium size will grow (shrink)

$$
\begin{gathered}
\frac{\partial \ln K}{\partial \phi}=\frac{1}{\phi^{2}} \ln \left[\mu\left(\frac{L_{W}}{L}\right)\right]>0 \\
\frac{\partial \ln K}{\partial \delta}=\frac{1}{\delta^{2}} \ln \left[1-\mu\left(\frac{L_{W}}{L}\right)\right]>0
\end{gathered}
$$

The following example illustrates this prediction. Suppose the team consists of a given fraction

of white players, $\left(\frac{L_{W}^{\prime}}{L}\right)$. If white fans' tastes strengthen ( $\phi$ rises), then their willingness to pay to see this fraction of white players perform rises. The returns to capital accumulation will rise, inducing authorities to build a larger facility. Using the same reasoning, if non-white fans' tastes strengthen ( $\delta$ rises), their willingness to pay to see the fraction $\left(1-\frac{L_{W}^{\prime}}{L}\right)$ of players perform will rise, leading to a larger stadium. Therefore, the model predicts that heightened customer discrimination will encourage greater investment. This is an unusual result because it differs from Becker's (1957) prediction regarding the relationship between the usage of labor and the degree of customer discrimination. Becker's model predicts that customer discrimination would not influence a firm's profitability because the firm would either assign minority workers to positions where they have no contact with customers or locate in markets dominated by customers with favorable preferences. 
The third set of predictions includes various interaction terms. Because the net return function includes the product of the constant elasticity demand function and the Cobb-Douglas production function, cross-partial derivatives of the demand for capital with respect to different pairs of explanatory variables will be non-zero. We focus in particular on two sets of interaction terms

1. The sensitivity of stadium size to a change in fan demographics will be influenced by team racial composition

$$
\frac{\partial^{2} Q}{\partial \mu \partial \frac{L_{W}}{L}} \neq 0
$$

If the fan market becomes whiter, then that can increase the effect that a team's adjustment of racial composition can have on stadium capacity. For example, a larger white fan share can generate a larger increase in stadium capacity when the team is $75 \%$ white versus when it is $50 \%$ white. It follows also that the sensitivity of stadium size to a change in team racial composition will be influenced by fan demographics. For example, stadium capacity could be more sensitive to an adjustment in the white team share when the fan market is $80 \%$ white versus when it is $60 \%$ white.

2. The sensitivity of stadium size to a changes in team racial composition or fan demographics will be influenced by the strength of fan racial tastes

$$
\frac{\partial^{2} Q}{\partial \mu \partial \phi} \neq 0, \frac{\partial^{2} Q}{\partial \mu \partial \delta} \neq 0, \frac{\partial^{2} Q}{\partial \frac{L_{W}}{L} \partial \phi} \neq 0, \frac{\partial^{2} Q}{\partial \frac{L_{W}}{L} \partial \delta} \neq 0
$$

For example, if the magnitude of white fan tastes for white teams rises, this can cause the marginal effect on stadium capacity of a change in team racial composition or a change in fan demographics to be greater.

Note that signs on these and other interaction terms usually require parameter restrictions. What is important about these interaction terms is that they imply the need for including interaction terms between the various explanatory variables in any empirical specification of stadium size.

\section{Empirical analysis}

Equation (12) above shows the determinants of the optimum stock of capital that will be put in place, based on the model derived above. This expression is a version of what Chirinko (1993) called the "Benchmark Model" of capital investment. To derive an empirically viable model of demand for capital investment from this expression, we would add adjustment costs to the capital demand 
function in order to bring dynamics into the model. However, we are not interested in exploring the dynamic process of investment in sports facilities in this paper; we are interested instead in analyzing the determinants of the optimum stock of capital put in place when a new sports facility is built. Instead of building dynamics into the model, we assume that capital adjustment costs are zero, and cities build facilities of the optimum size each time a new facility is built. Our basic empirical model is a log-linear version of equation (12) that relates the amount of capital put in place to relevant prices, quantities, and customer demand shifters identified by the theory. The basic empirical model is

$$
K_{i t}=\beta_{0}+\beta_{1} r_{t}+\beta_{2} R C_{i t}+\beta_{3} R T_{i t}+\gamma Z_{i t}+\theta D_{i t}+e_{i t}
$$

where $K_{i t}$ is the $\log$ of the amount of capital put in place in city $i$ in year $t, r_{t}$ is a measure of the cost of capital in year $t, R C_{i t}$ is a vector of variables that capture the racial characteristics of the population in city $i$ in year $t, R T_{i t}$ is a vector of variables that capture the racial characteristics of the sports team playing in the stadium in city $i$ in year $t, Z_{i t}$ is a vector of variables that shift the demand for the products produced by sports teams, and $D_{i t}$ is a vector of variables that capture other team and stadium specific factors in city $i$ in year $t$. The $\beta \mathrm{s}, \gamma \mathrm{s}$, and $\theta \mathrm{s}$ are vectors of unknown parameters to be estimated and $e_{i t}$ is a random variable capturing all other factors that affect the amount of capital put in place in city $i$ in year $t$. This error is assumed to be a mean zero random variable with non-constant variance. The heteroscedasticity comes from differences in city and market size.

Many empirical capital investment studies that use aggregate data assume that $e_{i t}$ is serially correlated. However, we estimate the parameters of equation (16) using micro data - data for specific capital investment projects - in a pooled sample of cross sections. Our pooled sample does not contain observations for every year in the sample period, as new sports facilities are built infrequently. Because of these features of the data, we assume that $e_{i t}$ is serially uncorrelated.

In this context, a number of variables could proxy for the amount of capital put in place when a new sports facility is built. The model derived above defines $K_{i t}$ as the quantity of capital used. Under this definition, either the capacity of the sports facility or the total cost of the sports facility would be appropriate variables to use as a proxy for $K_{i t}$. However, the cost of a seat in a basketball arena in Denver may not be the same as the cost of a seat in a football stadium in Miami, or a seat in a hockey arena in Buffalo. Alternatively, the average construction cost per seat could be used as a proxy for $K_{i t}$. Average cost per seat reflects factors like land acquisition costs, regional differences in wages paid to construction workers, and variation in real materials costs that affect stadium construction projects. We use total real construction cost in our empirical estimation of the parameters of equation (16).

The primary parameters of interest in equation (16) are elements of the vector $\beta_{2}$. These parameters capture the effect of variation in the racial composition of city $i$ in year $t$ on the amount of capital 
put in place by a sports team. The sign and significance of these elements of $\beta_{2}$ are related to the hypothesized effect of changes in the parameter $\mu$ in the model developed above (the white fan population share), and other factors related to racial preferences, on the optimum stock of capital. These tests are described in detail below.

\subsection{Data Description}

The data set used in this paper was constructed from a variety of sources. We began with the list of stadium and arena construction projects, including total construction costs, compiled by Keating (1999). This list of over 100 stadium construction and renovation projects over the period 1898-1997 was compiled by Keating from primary sources, including newspaper reports. We expanded Keating's data for the period 1998-2004 using the stadium and arena construction data in Long (2005) and augmented it with stadium capacity data from the Ballparks.com web site (www.ballparks.com). In general, the estimated construction cost reported by Keating (1999) and Long (2005) are similar. However, Long's estimates are more comprehensive and where these estimates differ we use the total cost estimates from Long (2005). Combining the data from these two sources yielded a sample of 187 individual facility construction and renovation projects for professional football, basketball, baseball and hockey teams in the United States over the period 1897-2004. 151 of these were new facility construction projects and 36 were renovations of existing facilities. Of these 151, 122 took place after the NFL, NBA and MLB were racially integrated in the late 1940s to early 1950s. Before integration, there were no minority athletes in professional sports, and the possibility of discrimination was greatly diminished. We focus on these 122 new sport facility construction projects.

Table 1: Summary Statistics - New Facility Construction and Teams

\begin{tabular}{lrrrrr} 
Sport & $\begin{array}{c}\text { Number of } \\
\text { Projects }\end{array}$ & $\begin{array}{c}\text { Millions of } \\
\$ 2004\end{array}$ & Capacity & Cost per seat & $\begin{array}{r}\% \text { of Team } \\
\text { non-white }\end{array}$ \\
\hline NFL & 31 & 249 & 68,074 & 3,633 & 35 \\
MLB & 34 & 164 & 45,254 & 5,062 & 26 \\
NBA & 41 & 177 & 18,710 & 9,206 & 58 \\
NHL & 16 & 152 & 17,864 & 8,448 & 4 \\
\hline \hline
\end{tabular}

Table 1 summarizes the stadium construction and renovation data in the sample, and the racial composition of teams in the sample. $34 \%$ of the 122 new facility construction projects in the sample were baseball stadiums, $31 \%$ were football stadiums, $41 \%$ were basketball arenas and $16 \%$ were hockey arenas. This taxonomy treats multi-purpose facilities - stadiums home to both football and baseball teams and arenas home to both basketball and hockey teams - as the home to a single sports team. 
There are 15 facilities in the sample that hosted both football and baseball teams and 19 facilities that hosted both basketball and hockey teams in the sample. A one-way analysis of variance indicates that the average cost per seat in basketball and hockey arenas is higher than the average cost per seat in baseball and football stadiums.

We augmented the stadium construction and capacity data with economic and demographic data for the cities that were hosts to these facilities from a variety of sources. Per capita personal income, population, and the racial composition of the population in each city were taken from the Decennial census for the period 1900-1939, from various issues of the County and City Data Book supplement to the Statistical Abstract of the United States for the period 1940-1968, and from the Bureau of Economic Analysis historical State and Local Personal Income statistics web site (http://www.bea.gov/bea/regional/statelocal.htm) for the period 1969-2004.

A measure of the real interest rate is needed in order to estimate the model. We constructed an estimate of the ex post real interest rate by subtracting the actual inflation rate from the Consumer Price Index over the previous year by the nominal interest rate on AAA rated corporate bonds. The other possible interest rate variable available over the sample period is the interest rate on municipal bonds. The results reported below were not sensitive to the choice of a nominal interest rate.

The primary parameters of interest are those on the variables reflecting the racial composition of teams and cities and racial preferences of fans, holding other factors constant. The prediction about the effect of fan prejudice on capital investment that emerges from the model is conditional on the fraction of non-white players on the team roster, so we estimate empirical models containing variables capturing both the racial composition of the teams and the racial composition of the city. We use three different variables to proxy for fan tastes for discrimination: the fraction of the local population that is white, an index of dissimilarity that captures the extent to which blacks disproportionately reside in some areas of a city relative to whites, and an index of isolation that reflects the exposure of blacks to whites in cities. The latter two variables were created by Cutler, Glaeser and Vigdor (1999). The fraction of the local population that is white has often been used in empirical studies of customer discrimination in labor markets (see Kahn (1991) for a discussion of measures of fan prejudice).

Simple measures of the racial composition of the population in each city may not reflect underlying attitudes about race. A city with a majority white population does not necessarily contain a large population of whites with a preference for watching sports teams composed of white players. In order to broaden the measures of fan racial preferences, we augmented the data set with variables reflecting the spatial segregation of blacks and whites in US cities developed by Cutler, Glaeser and Vigdor (1999). Cutler, Glaeser and Vigdor (1999) point out that the existence of "ghettos" in US cities can reflect racial discrimination and they develop several city-specific measures of spatial segregation using census data. We use two of these measures of racial segregation, an index of dissimilarity that captures 
the extent to which blacks disproportionately reside in some areas of a city relative to whites, and an index of isolation that reflects the exposure of blacks to whites in cities. For each new sports facility construction project in the sample, the dissimilarity index variable and the isolation index variable are the index values for the census immediately proceeding the opening of the facility.

The geographic unit of measurement in the sample is a metropolitan area. Our sample extends back beyond the period over which the Census Bureau defined Metropolitan Statistical Areas, which were only delineated after 1950. This makes the definition of a metropolitan area, in the context of published population and income data, difficult. Over the period 1969-2003, the city that is home to each stadium is defined as the current Standard Metropolitan Statistical Area that contains the stadium or arena. In the period 1950-1968, we use the Metropolitan Statistical Area for the appropriate period. Prior to 1950, we use the population and income data for the city that was home to the facility, based on the list of cities appearing in the Statistical Abstract of the United States for that year.

Capital investment projects are large undertakings and are typically financed by borrowing. Borrowing costs depend on the real interest rate, and estimates of the real interest rate require nominal interest rate data from financial markets and price data. Also, converting nominal capital spending variables to real terms requires price indexes. We augmented the data set with financial variables from the NBER Macro History database (http://www.nber.org/databases/macrohistory/contents/) and price indexes from the Bureau of Labor Statistics (http://www.bls.gov/bls/inflation.htm).

We also collected team specific data for the teams that played in the new facilities in the sample. These data include the winning percentage for the team over the five years prior to the facility opening and the fraction of the players who were non-white in the year the facility opened. The winning percentage variable was set to zero for expansion teams. The team racial composition variable was calculated by examining team photographs and player cards for the appropriate years. Based on these photographs, the fraction of each team that appeared to be non-white was calculated. Kahn's (1991) survey of the empirical literature on discrimination in sports indicates that this procedure is commonly used to identify the racial composition of sports teams.

Table 2 shows summary statistics for the other explanatory variables used in the empirical analysis of capital investment. Note that mean and standard deviation of the winning percent variable is for teams that played games in the previous five years; for expansion teams, the winning percent variable over the past five years was set to zero. According to Cutler, Glaeser and Vigdor (1999), a city has a ghetto if the index of dissimilarity has a value over .60 and the index of isolation has a value of over 0.03. Based on this measure, the average city in our sample contains a ghetto. 
Table 2: Summary Statistics, Other Covariates

\begin{tabular}{lrr} 
Variable & Mean & Standard Deviation \\
\hline Real Per Capita Income & 30,331 & 7,000 \\
Real Interest Rate & 1.91 & 2.10 \\
City Population & $2,987,969$ & 302,260 \\
Winning Percent, last 5 years & 0.511 & 0.108 \\
Domed Stadium & 0.08 & 0.275 \\
Facility in CBD & 0.24 & 0.427 \\
Fraction of City Population White & 0.75 & 0.202 \\
Dissimilarity Index & 0.70 & 0.137 \\
Isolation Index & 0.48 & 0.198 \\
\hline \hline
\end{tabular}

\subsection{Empirical Approach, Results and Discussion}

We estimated the parameters of equation (16) with data for the 122 observations on new sports stadium and arena construction projects described above. The model contains a cost of capital term $r_{t}$. A measure of the real interest rate is needed in order to estimate the model. We constructed an estimate of the ex post real interest rate by subtracting the actual inflation rate over the previous year by the nominal interest rate on AAA rated corporate bonds. The other possible interest rate variable available over the sample period is the interest rate on municipal bonds. The results are not sensitive to choice of a nominal interest rate.

The vector of demand shifters in equation $(16), D_{i t}$, contains the population of the city, the level of real per capita income in the city, and a measure of the past success of the team playing in the facility, the average winning percentage over the past 5 seasons. The vector of variables that capture facility specific factors that affect construction costs include: indicator variables for domed stadiums; whether the facility is located in the central business district of the city, where land costs may be higher; and an indicator variable for NBA and NHL arenas (facilities that, from Table 1, have lower average construction cost per seat.)

One econometric problem with a variable that reflects the racial composition of each team is that this variable could be correlated with the equation error term, $e_{i t}$, in equation (16). To control for this problem, we estimated equation (16) using an Instrumental Variables (IV) estimator that treats the racial composition of the team as endogenous. The instruments used were a time trend for the 
number of years elapsed since each league was racially integrated and indicator variables for NBA, MLB and NFL teams.

Columns two and three of Table 3 contain OLS and IV parameter estimates and P-values of the parameters in equation (16) when total real construction cost is used as the dependent variable. The standard errors underlying the reported P-values were corrected for heteroscedasticity using the White-Huber "sandwich" correction.

Table 3: Parameter Estimates of Equation (16)

Dependent Variable is Log of Total Real Construction Cost

\begin{tabular}{lrr|rr|rr} 
& \multicolumn{2}{c}{ OLS } & \multicolumn{2}{c}{ IV } & OLS \\
Variable & Parameter & P-value & Parameter & P-value & Parameter & P-value \\
\hline Team \% non-white & 0.004 & 0.002 & 0.005 & 0.024 & 0.009 & 0.002 \\
City Population \% white & -0.575 & 0.037 & -0.556 & 0.062 & -1.39 & 0.014 \\
Racial Dissimilarity Index & -0.020 & 0.000 & -0.019 & 0.000 & -0.017 & 0.000 \\
Team \% non-white x Pop. \% non-white & - & - & - & - & -1.94 & 0.014 \\
Real interest rate & 0.023 & 0.415 & 0.024 & 0.406 & 0.029 & 0.295 \\
Real Income per capita & 0.003 & 0.757 & 0.002 & 0.775 & 0.003 & 0.703 \\
Population (000) & 0.004 & 0.003 & 0.004 & 0.003 & 0.005 & 0.002 \\
Winning \%, last 5 years & 0.666 & 0.000 & 0.646 & 0.001 & 0.628 & 0.001 \\
Referendum & 0.348 & 0.000 & 0.345 & 0.000 & 0.359 & 0.000 \\
Domed Stadium & 0.563 & 0.000 & 0.559 & 0.000 & 0.551 & 0.000 \\
Facility in CBD & 0.322 & 0.004 & 0.319 & 0.005 & 0.328 & 0.003 \\
Facility is an arena & -0.303 & 0.006 & -0.311 & 0.005 & -0.300 & 0.005 \\
$R^{2} / N$ & 0.57 & 119 & 0.57 & 119 & 0.56 & 119 \\
\hline \hline
\end{tabular}

The estimated parameters on the demand and cost shifters are generally significant and correctly signed. Cities with larger populations build more expensive facilities. Cities with more successful teams build more expensive facilities. Domed stadiums are more expensive to build, and facilities built in the central business district of cities cost more. Arenas are less costly to build than stadiums. These estimated signs are consistent with standard neoclassical capital investment theory and the model developed above.

The parameters on the real interest rate and real per capita income are imprecisely estimated. The lack of precision on the real interest rate variable is probably due to the relatively poor quality of the nominal interest rate variables available over this long sample period, and the ex post real interest rate used in the model. Economic theory predicts that the expected inflation rate should be subtracted 
from the nominal interest rate in order to estimate the real interest rate. The actual inflation rate is equal to the expected inflation rate only under perfect foresight, a condition that probably does not hold over long periods of time. Despite this imprecise estimate, the model predicts that a measure of real interest rates belongs in the empirical model and omitting this variable might lead to bias in other parameter estimates.

Our regression results strongly confirm that sports facility size depends on the racial compositions of the team and fan population. Results from both OLS and IV estimation show that, all else equal, facility size is: (i) inversely related to the share of the team that is white; and (ii) inversely related to the share of the fan market that is white. According to the predictions of the model, the marginal effect of team racial composition on facility size can be positive or negative, depending on initial team racial composition, the racial composition of the the fan market, and the strength of white fan racial tastes relative to non-white fan tastes. The model also predicts that the marginal effect of fan racial share on facility size depends on team racial composition and relative white fan racial preferences. The estimated signs of the coefficients on the percentage share of the team that is non-white variable and the percentage share of the city's population that is white variable are both consistent with the model's predictions; whiter teams and fan populations apparently lead to smaller sports facilities, other things equal.

Our results confirm that fan racial tastes influence sports facility size. The parameter on the racial dissimilarity variable is negative and significant. The larger the index of racial dissimilarity in a city, the smaller will be the new sports facility, other things equal. Although we do not report the results for the index of racial isolation, the signs of the estimated parameter on this variable were also negative and significant for the OLS and IV models. We interpret this as evidence that customer racial discrimination affects capital investment, and that the primary mechanism is customer discrimination. Cutler, Glaeser and Vigdor (1999) point out that the existence of racial segregation in cities can be the "result of collective actions taken by whites to enforce separation from backs" (page 476), and that even in the absence of formal barriers to racial segregation that existed in the early twentieth century, persistent underlying racial preferences can make segregation persistent. In the context of our results, tastes for racial segregation in housing in a city may be related to tastes for customer discrimination in the city, holding the racial composition of the team constant. Our results are consistent with this, and support the predictions in the model developed earlier in the paper.

Finally, the theory developed above clearly indicates that interaction effects are important in this setting. We estimated a number of models that interacted the various racial composition variables used above. The results from this extension were a mixed bag of signs and significance. However, several of the interaction terms were significant. The fourth column on Table 3 shows one of these interaction models, where the interaction between the fraction of the team that is non-white is interacted with the 
fraction of the local population that is non-white. The parameter on the interaction term is negative and significant, and an F-test on the joint significance of the interaction term and the parameter on the variable capturing the fraction of the team that is non-white rejects the null hypothesis that the two are jointly equal to zero. The importance of interaction terms in the empirical model supports the predictions of the theoretical model.

The results shown on Table 3 are generally robust to alternative specifications. The estimated parameters, and the significance of these parameters are qualitatively similar if the log of total real construction costs is replaced with the log of the real cost per seat. The estimated parameter on an alternative measure of the real interest rate, based on municipal bond rates was also not statistically significant. We recognize that the theory developed above indicates that the size of the public subsidy has an effect on the optimum stock of capital. However, this variable is clearly correlated with the equation error term in equation (16), and we lack a good instrument to identify this variable. Including the fraction of public subsidy as an explanatory variable in equation (16) had no effect on the other estimated parameters, and the estimated parameter on this variable was not significant.

\section{Conclusions}

In this paper, we develop and test a capital investment model for sports facilities that links investment with racial discrimination by sports fans. The model is novel in that the effect of customer discrimination on capital investment has not been investigated in previous research. This omission is interesting, given the well-established complementarity of capital and labor in production and the extensive empirical evidence that discrimination affects labor markets. The empirical analysis generally supports the predictions that emerge from the model.

The paper contains evidence that the effect of customer discrimination in labor markets extends into capital markets. Becker's (1971) model of discrimination extended to decisions about capital investment predicts that customer's tastes for products produced by workers of the same race will affect firm's capital investment decisions. Evidence from the estimation of an empirical version of the optimality conditions that emerge from the model indicate that new stadiums and arenas built in cities with greater racial segregation tend to be smaller, and have lower total construction costs. This result is analogous to previously reported results in the literature that customer discrimination leads to lower wages in capital markets.

The evidence about the extent of discrimination in this paper has important implications for public policy, as well as for economists' understanding of the scope and consequences of discrimination. First, our results show that the scope of discrimination is broader than was previously suspected. Discrimination, in particular customer discrimination, affects both the wages of employees and the capital 
put in place by firms. If the results in this paper generalize to other settings, then minority owned and operated firms may not have as large a capital stock as they could in the absence of discrimination. Undercapitalization can affect both the earnings and productivity of workers and the economic returns to owners. Federal and state governments have devoted considerable resources to detecting and mitigating the effect of discrimination in labor markets. If the effects of customer discrimination extend to capital investment, then existing anti-discriminatory policies should be expanded to include the possibility that the capital structure of firms is also affected. Clearly, these results suggest that additional empirical research into the effects of discrimination on capital investment in other settings is warranted.

Finally, to date, no research has addressed the optimum size of sports facilities. Our results reveal some interesting information about the determinants of the optimal capital stock for sports teams. Our results indicate that the optimum capital investment in a sports facility increases with income per capita in the local market, with the population of the local market, and with the long-term success of the team playing in the facility. These results indicate that capital investment made by sports teams has similar characteristics to capital investment made by other firms.

\section{References}

Becker, G. (1971) The Economics of Discrimination, University of Chicago Press, Chicago, IL.

Bodvarsson, O. and Partridge, M. (2001) "A supply and demand model of co-worker, employer and customer discrimination," Labour Economics, 8(3): 389-416.

Chirinko, R. (1993) "Business Fixed Investment Spending: Modeling Strategies, Empirical Results, and Policy Implications," Journal of Economic Literature, 31(4): 1875-1911.

Coates, D. (2007) "Stadiums and Arenas: Economic development or Economic Distribution?" Contemporary Economic Policy, 25(4): 565-577.

Cutler, D. M., E. L. Glaeser, and J. L. Vigdor (1999), "The Rise and Decline of the American Ghetto," Journal of Political Economy, vol. 107, no. 3, 455-506.

Fort, R. (1997) "Direct Democracy and the Stadium Mess," in R. Noll and A. Zimbalist, eds., Sports, Jobs and Taxes: The Economic Impact of Sports Teams and Stadiums, Brookings Institution Press, Washington DC.

Goff, B., R. McCormick and R. Tollison (2002) "Racial Integration as an Innovation: Empirical Evidence From Sports Leagues," American Economic Review 92(1): 16-26. 
Groothius, P. A. and J. R. Hill (2004) "Exit Discrimination in the NBA: A Duration Analysis of Career Length," Economic Inquiry, 42(2): 341-349.

Keating, R. (1999) "Sports Pork: The Costly Relationship Between Major League Sports and Government," Cato Institute Policy Analysis paper no. 399.

Kahn, L. (1991) "Discrimination in Professional Sports: A Survey of the Literature," Industrial and Labor Relations Review, 44(3): 395-418.

Kanazawa, M. and J. Funk (2001) "Racial Discrimination in Professional Basketball: Evidence from Nielson Ratings," Economic Inquiry 39(4): 599-608.

Long, J. (2005) "Full Count: The Real Cost of Funding for Major League Sports Facilities," Journal of Sports Economics 6(2): 119-143.

O'Roark, B. (2001) "Capital Structure and Team Performance in Professional Baseball," Journal of Sports Economics, 2(2): 168-180.

Szymanski, S. (2000) "A Market Test for Discrimination in the English Professional Soccer Leagues," Journal of Political Economy, 108(3): 590-603. 